This is an author produced version of a paper published in Journal of Oral Rehabilitation. This paper has been peer-reviewed but does not include the final publisher proof-corrections or journal pagination.

Citation for the published paper:

Chrcanovic, Bruno; Albrektsson, Tomas; Wennerberg, Ann. (2016). Turned versus anodised dental implants : a meta-analysis. Journal of Oral

Rehabilitation, vol. 43, issue 9, p. null

URL: https://doi.org/10.1111/joor.12415

Publisher: Wiley

This document has been downloaded from MUEP (https://muep.mah.se) / DIVA (https://mau.diva-portal.org). 
1

2

3

4

5

6

7

8

9

10

11

12

13

14

15

16

17

18

19

20

21

22

23

24

25

26

27

28

29

30

31

32

33

34

35

36

37

38

39

40

41

42

43

44

45

46

47

48

49

50

51

52

53

54

55

56

57

58

59

60

\section{Turned versus anodized dental implants: a meta-analysis}

Running head: Turned vs. anodized implants: meta-analysis

REVIEW

Bruno Ramos Chrcanovic ${ }^{1 *}$

Tomas Albrektsson ${ }^{1,2}$

Ann Wennerberg ${ }^{1}$

${ }^{1}$ Department of Prosthodontics, Faculty of Odontology, Malmö University, Malmö, Sweden

${ }^{2}$ Department of Biomaterials, Göteborg University, Göteborg, Sweden

* Corresponding author:

Bruno Ramos Chrcanovic, Department of Prosthodontics, Faculty of Odontology, Malmö University, Carl Gustafs väg 34, SE-205 06, Malmö, Sweden. bruno.chrcanovic@mah.se; brunochrcanovic@hotmail.com Mobile: +46725541545 Fax: +46 406658503 


\section{SUMMARY}

The aim of this meta-analysis was to test the null hypothesis of no difference in the implant failure rates, marginal bone loss and postoperative infection for patients being rehabilitated by turned versus anodized-surface implants, against the alternative hypothesis of a difference. An electronic search without time or language restrictions was undertaken in November/2015. Eligibility criteria included clinical human studies, either randomized or not. Thirty-eight publications were included. The results suggest a risk ratio of $2.82(95 \% \mathrm{Cl} 1.95-4.06, P<0.00001)$ for failure of turned implants, when compared to anodized-surface implants. Sensitivity analyses showed similar results when only the studies inserting implants in maxillae or mandibles were pooled. There were no statistically significant effects of turned implants on the marginal bone loss (mean difference-MD $0.02,95 \% \mathrm{Cl}-0.16-0.20$; $P=0.82)$ in comparison to anodized implants. The results of a meta-regression considering the followup period as a covariate suggested an increase of the MD with the increase in the follow-up time (MD increase $0.012 \mathrm{~mm} / \mathrm{year})$, however without a statistical significance $(P=0.813)$. Due to lack of satisfactory information, meta-analysis for the outcome 'postoperative infection' was not performed. The results have to be interpreted with caution due to the presence of several confounding factors in the included studies.

\section{KEYWORDS}

Dental implants; turned implants; anodized implants; implant failure rate; marginal bone loss; metaanalysis 


\section{INTRODUCTION}

Albrektsson et al. (1) proposed six factors that have been generally accepted as especially important for the establishment of a reliable osseointegration, surface quality being one of them. As the implant surface is the first component to interact with the host, several surface modifications have been extensively investigated in the search for improved bone healing (2). Alterations in surface texture and chemistry are modifications used commonly to increase the biological response to implants (3-6). Anodic oxidation, an electrochemical process that increases the TiO2 surface layer and roughness, is one of the methods currently used to modify the surface of a dental implant. In this process, the implant is immersed in a suitable electrolyte and becomes an anode in an electrochemical cell. When a potential is applied, an ionic transport of charge is transferred through the cell, and an electrolytic reaction takes place at the anode, resulting in the growth of an oxide film $(7)$.

Some studies have compared the clinical outcomes of turned and anodized-surface dental implants. However, much of the research in the field is limited by small cohort size and short follow-up periods. In order to address this issue, meta-analyses are important, due to the increase of the sample size of individual trials to reach more precise estimates of the effects of interventions. We conducted a systematic review and meta-analysis to compare the survival rate of dental implants, marginal bone loss (MBL), and postoperative infection of turned and anodized-surface dental implants.

\section{MATERIALS AND METHODS}

This study followed the PRISMA Statement guidelines (8). A review protocol does not exist.

\section{Objective}

The purpose of the present review was to test the null hypothesis of no difference in the implant failure rates, MBL and postoperative infection for patients being rehabilitated by turned versus anodized-surface implants, against the alternative hypothesis of a difference. The focused question was elaborated by using the PICO format (Participants, Interventions, Comparisons and Outcomes): to compare three outcomes (implant failure rates, MBL, and postoperative infection) of clinical studies 
including patients undergoing implant-prosthetic rehabilitation comparing endosseous implants with turned and anodized surfaces.

\section{Search strategies}

An electronic search without time or language restrictions was undertaken in November 2015 in the following databases: PubMed/Medline, Web of Science, and the Cochrane Oral Health Group Trials Register. The following terms were used in the search strategy on PubMed/Medline, refined by selecting the term:

\{Subject AND Adjective\}

\{Subject: (dental implant OR oral implant [all fields])

AND

Adjective: (oxide-coated OR oxidized OR anodized OR anodization OR TiUnite [all fields])\}

The following terms were used in the search strategy on Web of Science, in all databases:

\{Subject AND Adjective\}

\{Subject: (dental implant OR oral implant [topic])

AND

Adjective: (oxide-coated OR oxidized OR anodized OR anodization OR TiUnite [topic])\}

The following terms were used in the search strategy on the Cochrane Oral Health Group Trials Register:

(((dental implant) OR oral implant)) AND (((((oxide-coated) OR oxidized) OR anodized) OR anodization) OR TiUnite)

\footnotetext{
A manual search of dental implants-related journals, including British Journal of Oral and Maxillofacial Surgery, Clinical Implant Dentistry and Related Research, Clinical Oral Implants Research, European Journal of Oral Implantology, Implant Dentistry, International Journal of Oral and
} 
Maxillofacial Implants, International Journal of Oral and Maxillofacial Surgery, International Journal of Periodontics and Restorative Dentistry, International Journal of Prosthodontics, Journal of Clinical Periodontology, Journal of Dental Research, Journal of Craniofacial Surgery, Journal of CranioMaxillofacial Surgery, Journal of Dentistry, Journal of Maxillofacial and Oral Surgery, Journal of Oral Implantology, Journal of Oral and Maxillofacial Surgery, Journal of Oral Rehabilitation, Journal of Periodontology, Journal of Prosthetic Dentistry, Oral Surgery Oral Medicine Oral Pathology Oral Radiology and Endodontology, and Quintessence International, was also performed.

The reference list of the identified studies and the relevant reviews on the subject were scanned for possible additional studies. Moreover, online databases providing information about clinical trials in progress were checked (clinicaltrials.gov; www.centerwatch.com/clinicaltrials; www.clinicalconnection.com).

\section{Inclusion and Exclusion Criteria}

Eligibility criteria included clinical human studies, either randomized or not, comparing implant failure rates, $\mathrm{MBL}$ and/or postoperative infection in any group of patients receiving turned (machined) and anodized-surface (TiUnite) implants, both from the same implant manufacturer (Nobel Biocare AB, Göteborg, Sweden). Based on the choice of comparing only implants from the same manufacturer, the focus is set on whether the clinical outcome and failure rate in similarly shaped implants, but with different surface characteristics of clinical relevance. For this review, implant failure represents the complete loss of the implant. Exclusion criteria were case reports, technical reports, biomechanical studies, finite element analysis (FEA) studies, animal studies, in vitro studies, and review papers.

\section{Study selection}

The titles and abstracts of all reports identified through the electronic searches were read independently by the three authors. For studies appearing to meet the inclusion criteria, or for which there were insufficient data in the title and abstract to make a clear decision, the full report was obtained. Disagreements were resolved by discussion between the authors.

\section{Quality assessment}


Quality assessment of the studies was executed according to the Newcastle-Ottawa scale (NOS), which is a quality assessment tool to use when observational studies are also included in systematic reviews (9). The NOS assesses nine items of the studies, divided in three main categories: (I) the selection of the study groups ([a] representativeness of the exposed cohort, which assesses whether the representativeness of the exposed individuals are representative of the average from some general population; [b] selection of external control, which assesses whether the control group was drawn from the same community as the exposed cohort; [c] ascertainment of exposure, which assesses whether the data comes from a secure record, a structure interview, or a written self-report; [d] outcome of interest not present at start), (II) comparability of cohorts (the study controls for the [a] main factor; and the study controls for any [b] additional factor) and (III) the ascertainment of either the exposure or outcome of interest for case-control or cohort studies respectively ([a] assessment of outcome, which assesses whether the data comes from a secure record, a structure interview, or a written self-report; [b] follow-up long enough; [c] adequacy of follow-up, which assesses the follow-up of the exposed and control cohorts to ensure that losses are not related to either the exposure or the outcome). It assigns a maximum of 4 stars for selection, a maximum of 2 stars for comparability, and a maximum of 3 stars for outcome. According to that quality scale, a maximum of 9 stars/points can be given to a study, and this score represents the highest quality, where six or more points were considered high quality.

Concerning the item 'follow-up long enough' of the component 'outcome', 5 years of follow-up was chosen to be enough for the outcome 'implant failure' to occur. To allow the survival and success of implants to be analyzed appropriately, a minimum of 5 years of follow-up is necessary (10).

\section{Data extraction and meta-analysis}

At least two review authors independently extracted data using specially designed data extraction forms. The data extraction forms were piloted on several papers; these were modified as required before use. Any disagreements were solved by discussion and a third review author was consulted where necessary.

From the studies included in the final analysis, the following data was extracted (when available): year of publication, study design, unicenter or multicenter study, number of patients, patients' age, follow-up, days of antibiotic prophylaxis, mouth rinse, implant healing period, failed and 
1

2

3

4

5

placed implants, period of failure (before or after loading), postoperative infection, MBL, implant surface modification, type of prosthetic rehabilitation, jaws receiving implants (maxilla and/or mandible). Contact with authors for possible missing data was performed. Implant failure and postoperative infection were the dichotomous outcomes measures evaluated. Weighted mean differences were used to construct forest plots of MBL, a continuous outcome. The statistical unit for 'implant failure' and 'MBL' was the implant, and for 'postoperative infection' was the patient. Whenever outcomes of interest were not clearly stated, the data were not used for analysis. The $\mathrm{I}^{2}$ statistic was used to express the percentage of the total variation across studies due to heterogeneity, with $25 \%$ corresponding to low heterogeneity, $50 \%$ to moderate and $75 \%$ to high. The inverse variance method was used for random-effects or fixed-effects model. Where statistically significant $(P<.10)$ heterogeneity is detected, a random-effects model was used to assess the significance of treatment effects. Where no statistically significant heterogeneity is found, analysis was performed using a fixed-effects model (11). The estimates of relative effect for dichotomous outcomes were expressed in risk ratio (RR) and in mean difference (MD) in millimeters for continuous outcomes, both with a $95 \%$ confidence interval $(\mathrm{Cl})$. Only if there were studies with similar comparisons reporting the same outcome measures was meta-analysis to be attempted. In the case where no events (or all events) are observed in both groups the study provides no information about relative probability of the event and is automatically omitted from the meta-analysis. In this (these) case(s), the term 'not estimable' is shown under the column of RR of the forest plot table. The software used here automatically checks for problematic zero counts, and adds a fixed value of 0.5 to all cells of study results tables where the problems occur.

In order to explore the possible heterogeneity of effect between studies, a meta-regression was performed in order to verify how a categorical study characteristic is associated with the intervention effects in the meta-analysis, but only when there were at least ten studies available with relevant variables.

A funnel plot (plot of effect size versus standard error) will be drawn. Asymmetry of the funnel plot may indicate publication bias and other biases related to sample size, although the asymmetry may also represent a true relationship between trial size and effect size. 
The data were analyzed using the statistical software Review Manager (version 5.3.3, The Nordic Cochrane Centre, The Cochrane Collaboration, Copenhagen, Denmark, 2014). Metaregressions (when possible) were performed by using the software OpenMeta[Analyst] (12).

\begin{abstract}
RESULTS
Literature search

The study selection process is summarized in Figure 1. The search strategy resulted in 1086 papers. A number of 312 articles were cited in more than one research of terms (duplicates). The three reviewers independently screened the abstracts for those articles related to the focus question. Of the resulted 774 studies, 736 were excluded for not being related to the topic, resulting in 38 entries. Additional hand-searching of the reference lists of selected studies yielded 8 additional papers. The full-text reports of the remaining 46 articles led to the exclusion of 8 because they did not meet the inclusion criteria ( 2 studies did not inform of the number of implants failures per group, 2 papers were earlier follow-up of the same study, 2 papers did not present separated numbers of the focused implants for one of the study groups, 1 paper was same study published in another journal, 1 study evaluated only replaced implants). Thus, a total of 38 publications were included in the review.
\end{abstract}

\title{
Description of the Studies
}

Four randomized clinical trials (13-16), six controlled clinical trials $(7,17-21)$, five prospective studies (22-26) and twenty-three retrospective analyses (27-49) were included in the meta-analysis. Detailed data of the 38 included studies are listed in Tables S1 and S2. Of the 38 studies comparing the procedures, a total of 43,680 dental implants were turned, with 3545 failures (8.11\%), and 23,306 implants had an anodized surface, with 456 failures (1.96\%). Nineteen studies (13, 15, 16, 20-22, 24, $25,28,32,34,35,39,41-45,47)$ provided information about the MBL separately by implant type, with mean and standard deviation. Only four studies $(7,20,26,44)$ provided information about postoperative infection. However, two $(7,20)$ of them didn't have any occurrences and only one study (44) provided information about which type of implants presented infections.

\section{Quality Assessment}


1

2

3

4

5

6

7

8

9

Quality assessment of the studies was executed according to the Newcastle-Ottawa scale (NOS), and the scores are summarized in Table S3. Twenty-three studies were of high quality and fifteen were of moderate quality.

\section{Meta-analysis and meta-regression}

In this study, a random-effects model was used to evaluate the implant failure in the comparison between the procedures, since statistically heterogeneity was found $\left(\mathrm{T}^{2}=0.66 ; x^{2}=\right.$ 213.31; $\left.I^{2}=84 \% ; P<0.00001\right)$. The insertion of turned implants statistically affected the implant failure rates in comparison to implants with an anodized surface (RR 2.82, 95\% Cl 1.95, 4.06, $P<$ 0.00001; Figure 2).

Since the effect size could differ depending on the insertion of implants in bone areas of different quality, a sensitivity analysis was performed. When only the studies inserting implants in maxillae were pooled, a RR of 2.54 resulted $\left(95 \% \mathrm{Cl} 1.32,4.89, P=0.005\right.$; heterogeneity: $\mathrm{T}^{2}=0.26, \mathrm{X}^{2}$ $=16.14, I^{2}=69 \%, P=0.006$, random-effects model; Figure 3 ), statistically affecting the implant failure rates $(P=0.005)$. When only the studies inserting implants in mandibles were pooled, a RR of 2.51 resulted $\left(95 \% \mathrm{Cl} 1.27,4.97, P=0.008\right.$; heterogeneity: $\mathrm{T}^{2}=0.50, \mathrm{x}^{2}=18.00, \mathrm{I}^{2}=44 \%, P=0.06$, random-effects model; Figure 4), also statistically affecting the implant failure rates $(P=0.008)$.

Another sensitivity analysis was performed taking into consideration the different scores for the NOS. When the 23 studies with 6 or more points in the NOS were pooled, a RR of 3.31 resulted (95\% Cl 2.18, 5.02, $P<0.00001$; heterogeneity: $\mathrm{T}^{2}=0.38, \mathrm{X}^{2}=65.24, \mathrm{I}^{2}=69 \%, P<0.00001$, randomeffects model), in comparison to a RR of $2.09\left(95 \% \mathrm{Cl} 1.40,3.14, P=0.0003\right.$; heterogeneity: $\mathrm{T}^{2}=$ $0.26, x^{2}=39.34, I^{2}=64 \%, P=0.0003$, random-effects model) when the 15 studies getting until 5 points in the NOS were pooled.

There were no apparent significant effects of turned implants on the MBL (MD 0.02, 95\% $\mathrm{Cl}$ $0.16,0.20 ; P=0.82$; heterogeneity: random-effects model, $\mathrm{T}^{2}=0.18 ; x^{2}=937.19 ; I^{2}=97 \% ; P<$ 0.00001, Figure 5) in comparison to implants with an anodized surface. The same resulted for sensitivity analyses taking into consideration the different scores for the NOS. When the studies with 6 or more points in the NOS were pooled, the MD was $0.00(95 \% \mathrm{Cl}-0.25,0.25 ; P=0.97$; heterogeneity: random-effects model, $\left.\mathrm{T}^{2}=0.30 ; \mathrm{X}^{2}=757.49 ; \mathrm{I}^{2}=97 \% ; P<0.00001\right)$, whereas the MD 
was $0.10\left(95 \% \mathrm{Cl}-0.15,0.35 ; P=0.42 ;\right.$ heterogeneity: random-effects model, $\mathrm{T}^{2}=0.07 ; \mathrm{X}^{2}=122.06 ; \mathrm{I}^{2}$ $=97 \% ; P<0.00001)$.

When a plotting considering the follow-up period as a covariate was performed, it was observed an increase of the MD of MBL with the increase in the follow-up time $(y=-0.008+0.001 x$; Figure 6). According to this statistical model, an increase of each year in follow-up time increases the MD in $0.012 \mathrm{~mm}(12 \times 0.001)$. However, the model was not statistically significant $(P=0.813)$.

Due to lack of enough information, meta-analysis for the outcomes 'postoperative infection' was not performed.

\section{Publication bias}

The funnel plot did not show asymmetry when the studies reporting the outcome 'implant failure' were analyzed (Figure 7), indicating possible absence of publication bias.

\section{DISCUSSION}

The purpose of the present review was to compare the implant failure rates, MBL and postoperative infection between turned and anodized-surface implants. One previous review (50) tried to compare the clinical outcome between these two types of implants. However, as the review only included RCTs, the analysis was hindered by the limited number of included studies, and the authors concluded that there is no evidence for a better clinical outcome of one surface over the other. On the other hand, the results of the present study suggest that the use of turned implants statistically affected the implant failure rates in comparison to implants with an anodized surface.

The higher failure rate of turned implants is hypothesized to be related to the small differences in the osseointegration process. TiUnite implants utilize moderately roughened surfaces characterized by a micro-porous thickened oxide layer (1 to $10 \mu \mathrm{m}$ thick), which is created through an electrochemical process. This open porous structure with various pits of variable dimensions ( 1 to 5 $\mu \mathrm{m}$ in diameter) creates a surface designed to allow greater bone-to-implant contact (33). A study (51) demonstrated a difference in bone healing between TiUnite and the turned Brånemark implants, with new bone formation directly on the surface of TiUnite implants, whereas it formed appositionally over osteotomy bone around the turned implants. These findings suggested an improved osseoconduction 
process of bone healing around the moderately rough-surface TiUnite implants (33). The fact is that when a biomaterial is inserted into living body, it absorbs proteins before cells adhere to its surface (52). These proteins significantly affect the attachment, adhesion, and spreading of osteoblasts, the cells that form bony tissues (53). For such cells, the implant's surface-charge influences their reactions to the implant, by affecting the type and amount of proteins attached on its surface (54). The enlarged surfaces, such as the anodized surface, provide better possibilities for microbiomechanical retention due to larger surface and thus more retention for proteins to attach and new bone formation. It is a matter of debate whether these differences in the early osseointegration process between these two surfaces may have significant impact on the long-term outcome of the implants.

The present results suggest that turned implants have a statistically significant higher failure rates in relation to anodized implants regardless whether the implants were placed in maxilla or mandible. The results are not in agreement with the results of Balshe et al. (33), who observed that turned implants performed better than anodized implants in the mandible, while the anodized implants performed better in the maxilla. However, a histological study of bone response between oxidized and turned titanium implants in human jawbone (55) supports the findings of the present meta-analysis concerning the similar outcome in both jaws. In this study, twenty patients received one test (TiUnite) and one control (turned Brånemark implant) micro-implant. After a healing time, the microimplants and the surrounding tissue were removed with a trephine bur and the histomorphometric evaluation demonstrated significantly higher bone-to-implant contact for the oxidized implants, both in the maxilla and in the mandible. It was also suggested that turned implants have a statistically significant higher failure rates in relation to anodized implants regardless whether only studies having or not having high NOS quality scores were pooled together.

Concerning MBL, the beneficial effect of rough implant surfaces on peri-implant bone formation is considered to be based on the changes in microtopography and subsequent alterations of surface energy that result in increased interaction with the adjacent biological environment by adsorption of proteins and blood components which in turn can enhance cell attachment and implant integration (56). However, the results of the present meta-analysis suggesting no apparent significant effects of turned implants on the MBL in comparison to anodized implants challenge this statement and the results of many clinical trials comparing MBL of turned and TiUnite implants $(16,17,22,24$, $25,28,39,41)$. A possible reason is the fact that some studies may lack statistical power, given the 
small number of patients per group in the clinical trials comparing the techniques. Moreover, it was reported that a surface roughness of more than $2 \mu \mathrm{m}(\mathrm{Sa})$ is associated with a higher risk of periimplantitis (57). Rougher implant surfaces are more susceptible to accumulation of bacteria on hard surfaces $(58,59)$. Bacterial infection, characterized as bacterial colonization and biofilm formation on dental implants, is an important risk factor for peri-implantitis. A roughened surface does not only increase the susceptibility for peri-implantitis, but also reduces the treatment efficacy of the bacteria biofilm (60). The prevalence of peri-implantitis with a TiUnite surface is not higher than turned surface, but once there is a peri-implantitis the progression is increased compared to other surfaces (61). Hence, moderate surface modifications may improve implant therapy in terms of speeding up the treatment, but may be disadvantageous for the patients prone to peri-implantitis (39). It is important to stress that the difference in implant surface is not the only factor playing a role in MBL, but the mechanisms behind such bone loss are most likely multifactorial and may be also be explained by remodeling as part of implant healing, the response to loading, ongoing atrophy after tooth loss, infection, or by other factors (44).

The statistical heterogeneity stands for the variability in the intervention effects being evaluated in the different studies, and is a consequence of clinical or methodological diversity, or both, among the studies. The high level of heterogeneity observed when the outcome 'implant failure' was analyzed is not surprising, given the variability of the included studies. For this reason, a randomeffects model was also used to incorporate heterogeneity among studies. However, it is important to stress that care must be taken in the interpretation of the chi-squared test, since it has low power in the (common) situation of a meta-analysis when studies have small sample size or are few in number. This means that while a statistically significant result may indicate a problem with heterogeneity, a non-significant result must not be taken as evidence of no heterogeneity (62). Some argue that, since clinical and methodological diversity always occur in a meta-analysis, statistical heterogeneity is inevitable (63). Thus, the test for heterogeneity is irrelevant to the choice of analysis; heterogeneity will always exist whether or not we happen to be able to detect it using a statistical test (62).

Limitations of the present study. The results of the present study have to be interpreted with caution because of its limitations. First of all, several confounding factors may have affected the outcomes and not just the fact that implants had turned and anodized surfaces. The impact of these variables on the implant survival rate, postoperative infection and $M B L$ is difficult to estimate if these 
1

2

3

4

5

6

factors are not identified separately between the two different implant types in order to perform a metaregression analysis. The lack of control of the confounding factors limited the potential to draw robust conclusions. Second, most of the included studies had a retrospective design. As all data from a retrospective study rely on the accuracy of the original examination and documentation, there are problems were manifested by the gaps in information and incomplete records, because items may have been excluded in the initial examination or not recorded in the medical chart. In a retrospective study is difficult to assess the adverse effects of implant surface differences on the prognosis of implants purely on the basis of implant failure because of the multifactorial genesis of implant failure (64). Third, some of included studies are characterized by a low level of specificity, i.e. the assessment of the implant surface as a complicating factor for dental implants was not the main focus of the investigation. Fourth, much of the research in the field is limited by small cohort size and short followup periods. Short follow-up periods might have led to an underestimation of actual failures, as longer follow-up periods can lead to an increase in the failure rate, especially if it extended beyond functional loading, because other prosthetic factors can influence implant failure from that point onward. However, it is hard to define what it would be considered a short follow-up period to evaluate implant failures. Furthermore, the quality assessment tool used here has received criticism $(65,66)$. Among other issues, there is no clear explanation for the identification of the threshold score for distinguishing the quality of the studies. However, one has to consider that a perfect quality assessment tool does not exist. Scales vary considerably in dimensions covered and complexity. Many scales include items for which there is little evidence that they are related to the internal validity of a trial (67). Still, the NOS is an indicated quality assessment tool for use on nonrandomized studies included in systematic reviews. The continued improvement of the scale by the authors of NOS would provide a better validity assessment of it.

The authors believe that new research efforts should be concentrated in large cohort longterm studies comparing failure rates and MBL between implants of moderately rough surfaces. The use of turned implants has been abandoned in several places (46), even though it still has its place in some countries and is considered as the 'golden standard' of comparison between implants of different surface treatments. It is also valid to incorporate a clear distinction of multiple confounding factors suggested to have some influence on the implant failure rates, such as smoking (68), bruxism 
(69), and the history of periodontal disease (70), as the clinical outcome may vary when other factors are taken into consideration.

\section{CONCLUSION}

Within the limitations of the existing investigations, the present study suggests that turned implants have a statistically higher probability to fail than anodized-surface implants, regardless whether the implants were placed in maxilla or mandible, or when studies having or not having high quality scores were pooled together. There were no statistically significant effects of turned implants on the MBL in comparison to anodized implants. A comparison of postoperative infection between the implant types was not possible, due to lack of enough information. The reliability and validity of the data collected, the limitations of the quality assessment tool, and the potential for biases and confounding factors are some of the shortcomings of the present study. 


\section{ACKNOWLEDGEMENTS}

The authors would like to thank Dr. Torsten Jemt for providing missing information about his study.

\section{ETHICAL APPROVAL}

Not applicable.

\section{SOURCE OF FUNDING}

None.

\section{CONFLICT OF INTERESTS}

There are no conflicts of interest.

\section{REFERENCES}

1. Albrektsson T, Brånemark PI, Hansson HA, Lindström J. Osseointegrated titanium implants. Requirements for ensuring a long-lasting, direct bone-to-implant anchorage in man. Acta Orthop Scand. 1981;52:155-170.

2. Wennerberg A, Albrektsson T. On implant surfaces: a review of current knowledge and opinions. Int J Oral Maxillofac Implants. 2010;25:63-74.

3. Chrcanovic BR, Pedrosa AR, Martins MD. Chemical and topographic analysis of treated surfaces of five different commercial dental titanium implants. Materials Res. 2012;15:372-382.

4. Chrcanovic BR, Leão NLC, Martins MD. Influence of different acid etchings on the superficial characteristics of Ti sandblasted with Al2O3. Materials Res. 2013;16:1006-1014.

5. Chrcanovic BR, Martins MD. Study of the influence of acid etching treatments on the superficial characteristics of Ti. Materials Res. 2014;17:373-380.

6. Chrcanovic BR, Wennerberg A, Martins MD. Influence of temperature and acid etching time on the superficial characteristics of Ti. Materials Res. 2015;18:963-970.

7. Aalam AA, Nowzari H. Clinical evaluation of dental implants with surfaces roughened by anodic oxidation, dual acid-etched implants, and machined implants. Int J Oral Maxillofac Implants. 2005;20:793-798. 
8. Moher D, Liberati A, Tetzlaff J, Altman DG, Grp P. Preferred Reporting Items for Systematic Reviews and Meta-Analyses: The PRISMA Statement. Ann Intern Med. 2009;151:264-269, W264.

9. Wells GA, Shea B, O'Connell D, Peterson J, Welch V, Losos M et al. The Newcastle-Ottawa Scale (NOS) for assessing the quality of nonrandomised studies in meta-analyses. http://www.ohri.ca/programs/clinical_epidemiology/oxford.asp. accessed on August 27, 2014, 2014.

10. Needleman I, Chin S, O'Brien T, Petrie A, Donos N. Systematic review of outcome measurements and reference group(s) to evaluate and compare implant success and failure. $\mathrm{J}$ Clin Periodontol. 2012;39 Suppl 12:122-132.

11. Egger M, Smith GD. Principles of and procedures for systematic reviews. In: Egger M, Smith GD, Altman DG, eds. Systematic Reviews in Health Care: Meta-analysis in Context. London: BMJ books; 2003: 23-42.

12. Wallace BC, Dahabreh IJ, Trikalinos TA, Lau J, Trow P, Schmid CH. Closing the Gap between Methodologists and End-Users: R as a Computational Back-End. J Statist Softw. 2012;49:1-15.

13. Fung K, Marzola R, Scotti R, Tadinada A, Schincaglia GP. A 36-month randomized controlled split-mouth trial comparing immediately loaded titanium oxide-anodized and machined implants supporting fixed partial dentures in the posterior mandible. Int $\mathrm{J}$ Oral Maxillofac Implants. 2011;26:631-638.

14. Nicu EA, Van Assche N, Coucke W, Teughels W, Quirynen M. RCT comparing implants with turned and anodically oxidized surfaces: a pilot study, a 3-year follow-up. J Clin Periodontol. 2012;39:1183-1190.

15. Van Assche N, Coucke W, Teughels W, Naert I, Cardoso MV, Quirynen M. RCT comparing minimally with moderately rough implants. Part 1: clinical observations. Clin Oral Implants Res. 2012;23:617-624.

16. Rocci A, Rocci M, Rocci C, Scoccia A, Gargari M, Martignoni M et al. Immediate loading of Branemark system TiUnite and machined-surface implants in the posterior mandible, part II: a randomized open-ended 9-year follow-up clinical trial. Int $\mathrm{J}$ Oral Maxillofac Implants. 2013;28:891-895. 
17. Attard NJ, David LA, Zarb GA. Immediate loading of implants with mandibular overdentures: oneyear clinical results of a prospective study. Int J Prosthodont. 2005;18:463-470.

18. Jungner $M$, Lundqvist $P$, Lundgren $S$. Oxidized titanium implants (Nobel Biocare TiUnite) compared with turned titanium implants (Nobel Biocare mark III) with respect to implant failure in a group of consecutive patients treated with early functional loading and two-stage protocol. Clin Oral Implants Res. 2005;16:308-312.

19. Östman PO, Hellman M, Sennerby L. Direct implant loading in the edentulous maxilla using a bone density-adapted surgical protocol and primary implant stability criteria for inclusion. Clin Implant Dent Relat Res. 2005;7 Suppl 1:S60-S69.

20. Fröberg KK, Lindh C, Ericsson I. Immediate loading of Branemark System Implants: a comparison between TiUnite and turned implants placed in the anterior mandible. Clin Implant Dent Relat Res. 2006;8:187-197.

21. Östman PO, Hellman M, Sennerby L. Immediate occlusal loading of implants in the partially edentate mandible: a prospective 1-year radiographic and 4-year clinical study. Int $\mathrm{J}$ Oral Maxillofac Implants. 2008;23:315-322.

22. Vanden Bogaerde L, Pedretti G, Dellacasa P, Mozzati M, Rangert B, Wendelhag I. Early function of splinted implants in maxillas and posterior mandibles, using Branemark System Tiunite implants: an 18-month prospective clinical multicenter study. Clin Implant Dent Relat Res. 2004;6:121-129.

23. Calandriello R, Tomatis M. Simplified treatment of the atrophic posterior maxilla via immediate/early function and tilted implants: A prospective 1-year clinical study. Clin Implant Dent Relat Res. 2005;7 Suppl 1:S1-S12.

24. Maló P, de Araújo Nobre M, Rangert B. Implants placed in immediate function in periodontally compromised sites: a five-year retrospective and one-year prospective study. J Prosthet Dent. 2007;97:S86-S95.

25. Liddelow G, Henry P. The immediately loaded single implant-retained mandibular overdenture: a 36-month prospective study. Int J Prosthodont. 2010;23:13-21.

26. Balshi TJ, Wolfinger GJ, Wulc D, Balshi SF. A prospective analysis of immediate provisionalization of single implants. J Prosthodont. 2011;20:10-15. 
27. Renouard F, Nisand D. Short implants in the severely resorbed maxilla: a 2-year retrospective clinical study. Clin Implant Dent Relat Res. 2005;7 Suppl 1:S104-S110.

28. Watzak G, Zechner W, Busenlechner D, Arnhart C, Gruber R, Watzek G. Radiological and clinical follow-up of machined- and anodized-surface implants after mean functional loading for 33 months. Clin Oral Implants Res. 2006;17:651-657.

29. Alsaadi G, Quirynen M, Komarek A, van Steenberghe D. Impact of local and systemic factors on the incidence of oral implant failures, up to abutment connection. J Clin Periodontol. 2007;34:610617.

30. Balshi SF, Wolfinger GJ, Balshi TJ. A retrospective analysis of 44 implants with no rotational primary stability used for fixed prosthesis anchorage. Int J Oral Maxillofac Implants. 2007;22:467471.

31. Alsaadi G, Quirynen M, Komarek A, van Steenberghe D. Impact of local and systemic factors on the incidence of late oral implant loss. Clin Oral Implants Res. 2008;19:670-676.

32. Friberg B, Jemt T. Rehabilitation of edentulous mandibles by means of five TiUnite implants after one-stage surgery: a 1-year retrospective study of 90 patients. Clin Implant Dent Relat Res. 2008;10:47-54.

33. Balshe AA, Assad DA, Eckert SE, Koka S, Weaver AL. A retrospective study of the survival of smooth- and rough-surface dental implants. Int J Oral Maxillofac Implants. 2009;24:1113-1118.

34. Eliasson A, Blomqvist F, Wennerberg A, Johansson A. A retrospective analysis of early and delayed loading of full-arch mandibular prostheses using three different implant systems: clinical results with up to 5 years of loading. Clin Implant Dent Relat Res. 2009;11:134-148.

35. Friberg B, Jemt T. Clinical experience of TiUnite implants: a 5-year cross-sectional, retrospective follow-up study. Clin Implant Dent Relat Res. 2010;12 Suppl 1:e95-e103.

36. Hatano N, Yamaguchi M, Yaita T, Ishibashi T, Sennerby L. New approach for immediate prosthetic rehabilitation of the edentulous mandible with three implants: a retrospective study. Clin Oral Implants Res. 2011;22:1265-1269.

37. Maló P, de Araújo Nobre M. Implants (3.3 mm diameter) for the rehabilitation of edentulous posterior regions: a retrospective clinical study with up to 11 years of follow-up. Clin Implant Dent Relat Res. 2011;13:95-103. 
38. Sanchez-Garces MA, Costa-Berenguer X, Gay-Escoda C. Short implants: a descriptive study of 273 implants. Clin Implant Dent Relat Res. 2012;14:508-516.

39. Arnhart C, Dvorak G, Trefil C, Huber C, Watzek G, Zechner W. Impact of implant surface topography: a clinical study with a mean functional loading time of 85 months. Clin Oral Implants Res. 2013;24:1049-1054.

40. Balshi TJ, Wolfinger GJ, Slauch RW, Balshi SF. A retrospective comparison of implants in the pterygomaxillary region: implant placement with two-stage, single-stage, and guided surgery protocols. Int J Oral Maxillofac Implants. 2013;28:184-189.

41. Polizzi G, Gualini F, Friberg B. A two-center retrospective analysis of long-term clinical and radiologic data of TiUnite and turned implants placed in the same mouth. Int J Prosthodont. 2013;26:350-358.

42. Sayardoust S, Gröndahl K, Johansson E, Thomsen P, Slotte C. Implant survival and marginal bone loss at turned and oxidized implants in periodontitis-susceptible smokers and neversmokers: a retrospective, clinical, radiographic case-control study. J Periodontol. 2013;84:17751782.

43. Jungner M, Legrell PE, Lundgren S. Follow-up study of implants with turned or oxidized surfaces placed after sinus augmentation. Int J Oral Maxillofac Implants. 2014;29:1380-1387.

44. Jungner $M$, Lundqvist $P$, Lundgren $S$. A retrospective comparison of oxidized and turned implants with respect to implant survival, marginal bone level and peri-implant soft tissue conditions after at least 5 years in function. Clin Implant Dent Relat Res. 2014;16:230-237.

45. Friberg B, Jemt T. Rehabilitation of edentulous mandibles by means of osseointegrated implants: a 5-year follow-up study on one or two-stage surgery, number of implants, implant surfaces, and age at surgery. Clin Implant Dent Relat Res. 2015;17:413-424.

46. Jemt T, Olsson M, Franke Stenport V. Incidence of First Implant Failure: A Retroprospective Study of 27 Years of Implant Operations at One Specialist Clinic. Clin Implant Dent Relat Res. 2015;17 Suppl 2:e501-510.

47. Maló $\mathrm{P}$, de Araújo Nobre M, Gonçalves $\mathrm{Y}$, Lopes A. Long-Term Outcome of Implant Rehabilitations in Patients with Systemic Disorders and Smoking Habits: A Retrospective Clinical Study. Clin Implant Dent Relat Res. 2015. doi: 10.1111/cid.12346 
48. Maló P, de Araújo Nobre M, Lopes A, Ferro A, Gravito I. Single-Tooth Rehabilitations Supported by Dental Implants Used in an Immediate-Provisionalization Protocol: Report on Long-Term Outcome with Retrospective Follow-Up. Clin Implant Dent Relat Res. 2015;17 Suppl 2:e511-519.

49. Maló P, de Araújo Nobre M, Lopes A, Queridinha B, Ferro A, Gravito I. Axial Implants in Immediate Function for Partial Rehabilitation in the Maxilla and Mandible: A Retrospective Clinical Study Evaluating the Long-Term Outcome (Up to 10 Years). Implant Dent. 2015;24:557-564.

50. Esposito M, Ardebili Y, Worthington HV. Interventions for replacing missing teeth: different types of dental implants. Cochrane Database Syst Rev. 2014;7:Cd003815.

51. Zechner W, Tangl S, Furst G, Tepper G, Thams U, Mailath G et al. Osseous healing characteristics of three different implant types. Clin Oral Implants Res. 2003;14:150-157.

52. Brash JL, Horbett TA. Proteins at interfaces: current issues and future prospects. In: Brash JL, Horbett TA, eds. Proteins at Interfaces: Physicochemical and Biochemical Studies. Washington D.C.: American Chemical Society; 1987: 1-33.

53. Anselme K. Osteoblast adhesion on biomaterials. Biomaterials. 2000;21:667-681.

54. Hing KA. Bone repair in the twenty-first century: biology, chemistry or engineering? Philos Trans A Math Phys Eng Sci. 2004;362:2821-2850.

55. Ivanoff CJ, Widmark G, Johansson C, Wennerberg A. Histologic evaluation of bone response to oxidized and turned titanium micro-implants in human jawbone. Int $\mathrm{J}$ Oral Maxillofac Implants. 2003;18:341-348.

56. Boukari A, Francius G, Hemmerle J. AFM force spectroscopy of the fibrinogen adsorption process onto dental implants. J Biomed Mater Res A. 2006;78:466-472.

57. Becker W, Becker BE, Ricci A, Bahat O, Rosenberg E, Rose LF et al. A prospective multicenter clinical trial comparing one- and two-stage titanium screw-shaped fixtures with one-stage plasmasprayed solid-screw fixtures. Clin Implant Dent Relat Res. 2000;2:159-165.

58. Teughels W, Van Assche N, Sliepen I, Quirynen M. Effect of material characteristics and/or surface topography on biofilm development. Clin Oral Implants Res. 2006;17 Suppl 2:68-81.

59. Burgers R, Gerlach T, Hahnel S, Schwarz F, Handel G, Gosau M. In vivo and in vitro biofilm formation on two different titanium implant surfaces. Clin Oral Implants Res. 2010;21:156-164. 
60. Lin HY, Liu Y, Wismeijer D, Crielaard W, Deng DM. Effects of oral implant surface roughness on bacterial biofilm formation and treatment efficacy. Int J Oral Maxillofac Implants. 2013;28:12261231.

61. Dagorne C, Malet J, Bizouard G, Mora F, Range H, Bouchard P. Clinical evaluation of two dental implant macrostructures on peri-implant bone loss: a comparative, retrospective study. Clin Oral Implants Res. 2015;26:307-313.

62. Higgins JPT, Green S, Cochrane Collaboration. Cochrane handbook for systematic reviews of interventions. Chichester, England ; Hoboken, NJ: Wiley-Blackwell; 2008.

63. Higgins JP, Thompson SG, Deeks JJ, Altman DG. Measuring inconsistency in meta-analyses. BMJ. 2003;327:557-560.

64. Chrcanovic BR, Albrektsson T, Wennerberg A. Reasons for failures of oral implants. J Oral Rehabil. 2014;41:443-476.

65. Stang A. Critical evaluation of the Newcastle-Ottawa scale for the assessment of the quality of nonrandomized studies in meta-analyses. Eur J Epidemiol. 2010;25:603-605.

66. Hartling L, Milne A, Hamm MP, Vandermeer B, Ansari M, Tsertsvadze A et al. Testing the Newcastle Ottawa Scale showed low reliability between individual reviewers. J Clin Epidemiol. 2013;66:982-993.

67. Jüni $P$, Altman DG, Egger M. Systematic reviews in health care: Assessing the quality of controlled clinical trials. Bmj. 2001;323:42-46.

68. Chrcanovic BR, Albrektsson T, Wennerberg A. Smoking and dental implants: A systematic review and meta-analysis. J Dent. 2015;43:487-498.

69. Chrcanovic BR, Kisch J, Albrektsson T, Wennerberg A. Bruxism and dental implant treatment complications: a retrospective comparative study of 98 bruxer patients and a matched group. Clin Oral Implants Res. 2016. doi: 10.1111/clr.12844

70. Chrcanovic BR, Albrektsson T, Wennerberg A. Periodontally compromised vs. periodontally healthy patients and dental implants: A systematic review and meta-analysis. J Dent. 2014;42:1509-1527. 


\section{FIGURE CAPTIONS}

Figure 1. Study screening process.

Figure 2. Forest plot for the event 'implant failure'.

Figure 3. Forest plot for the event 'implant failure', when only the studies evaluating implants inserted in maxillae only were pooled.

Figure 4. Forest plot for the event 'implant failure', when only the studies evaluating implants inserted in mandibles only were pooled.

Figure 5. Forest plot for the event 'marginal bone loss'.

Figure 6. Scatter plot for the meta-regression with the association between the mean differences (in millimeters) of the marginal bone loss between the two implants (turned vs. anodized) and the followup time (in months). Circles indicate individual studies, and the size of the circles indicates the weight of each study.

Figure 7. Funnel plot for the studies reporting the outcome event 'implant failure' (RR - risk ratio; SE standard error). 
1081 records identified through database searching
5 additional records identified through other sources

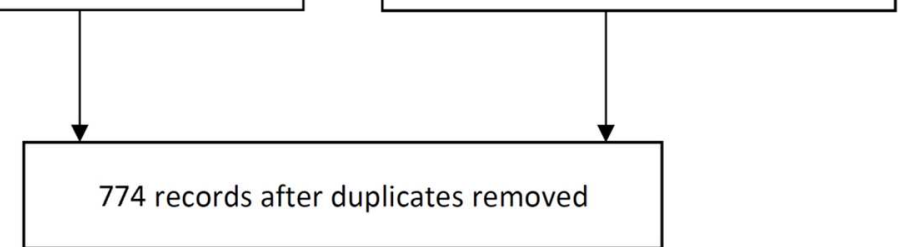

736 records excluded

38 records screened

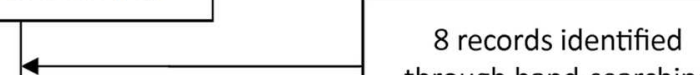
through hand-searching

46 full-text articles assessed for eligibility

8 full-text articles excluded: 2 did not inform the number of failures per group 2 earlier follow-up 2 did not present separated 38 studies included in qualitative synthesis numbers of the focused implants for one of the study groups 1 repeated 1 evaluated only replaced

38 studies included in implants quantitative synthesis (meta-analysis)

Figure 1 . Study screening process. $119 \times 122 \mathrm{~mm}$ (300 x 300 DPI) 


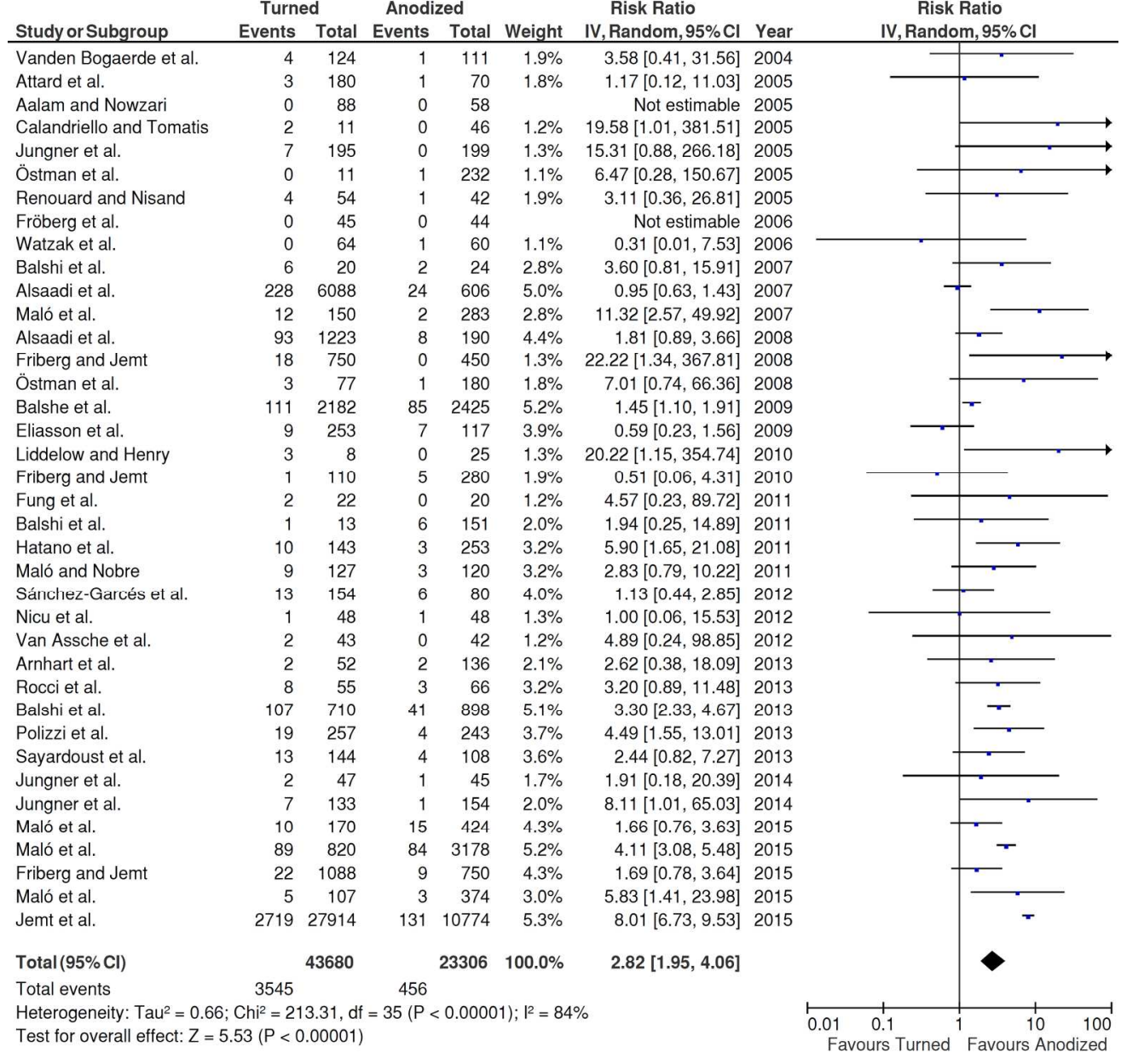

Figure 2. Forest plot for the event 'implant failure'. $185 \times 178 \mathrm{~mm}(300 \times 300$ DPI $)$ 
Figure 3. Forest plot for the event 'implant failure', when only the studies evaluating implants inserted in maxillae only were pooled.

$54 \times 15 \mathrm{~mm}(300 \times 300 \mathrm{DPI})$ 
Figure 4. Forest plot for the event 'implant failure', when only the studies evaluating implants inserted in mandibles only were pooled. $78 \times 33 \mathrm{~mm}(300 \times 300 \mathrm{DPI})$ 
Figure 5. Forest plot for the event 'marginal bone loss'. $125 \times 78 \mathrm{~mm}(300 \times 300 \mathrm{DPI})$ 


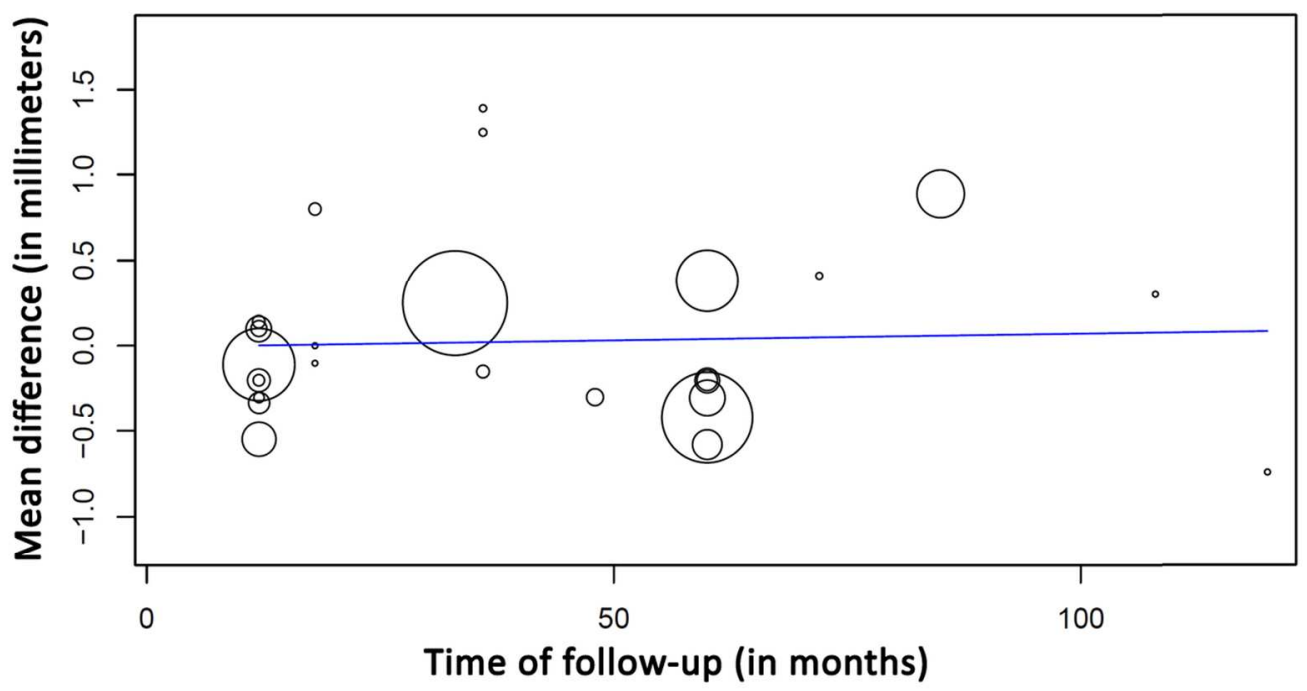

Figure 6. Scatter plot for the meta-regression with the association between the mean differences (in millimeters) of the marginal bone loss between the two implants (turned vs. anodized) and the follow-up time (in months). Circles indicate individual studies, and the size of the circles indicates the weight of each study.

$108 \times 56 \mathrm{~mm}(300 \times 300 \mathrm{DPI})$ 
1

2

3

4

5

6

7

8

9

10

11

12

13

14

15

16

17

18

19

20

21

22

23

24

25

26

27

28

29

30

31

32

33

34

35

36

37

38

39

40

41

42

43

44

45

46

47

48

49

50

51

52

53

54

55

56

57

58

59

60

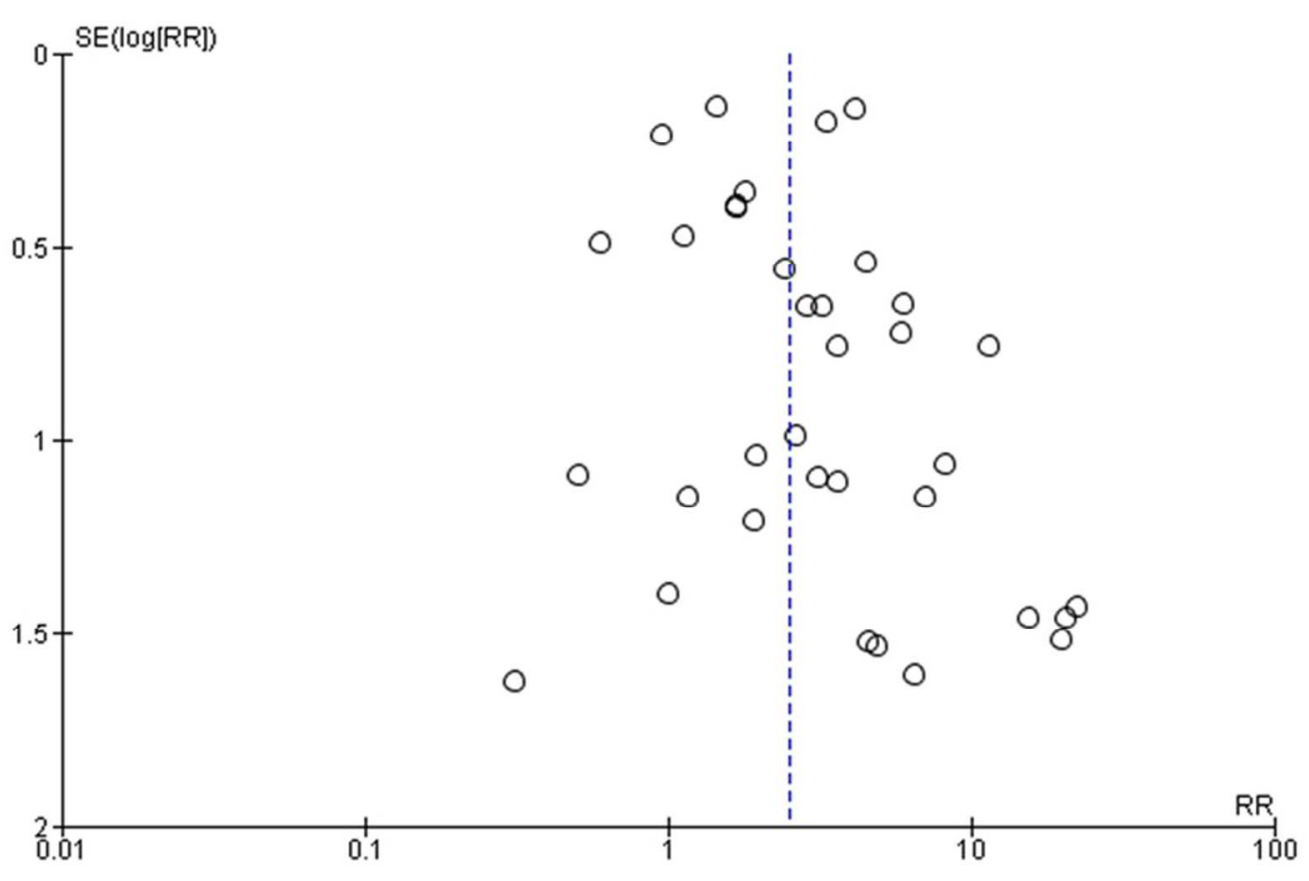

Figure 7. Funnel plot for the studies reporting the outcome event 'implant failure' (RR - risk ratio; SE standard error).

$65 \times 42 \mathrm{~mm}(300 \times 300$ DPI $)$ 